\title{
EFFECTS OF SEROTONIN ON THE GENERATION OF THE MOTOR PROGRAM FOR SWIMMING BY THE MEDICINAL LEECH ${ }^{1}$
}

\author{
ALAN L. WILLARD ${ }^{2}$
}

Biology Department, University of California at San Diego, La Jolla, California 92093

\begin{abstract}
I have examined the effects of serotonin on the generation of the motor program for swimming by the medicinal leech, Hirudo medicinalis, using both intact animals and isolated nerve cords. In normal saline, isolated nerve cords rarely produced episodes of the motor program for swimming except in response to electrical stimulation of swim-initiating interneurons or of segmental nerves; saline containing micromolar concentrations of serotonin caused isolated nerve cords to produce episodes of the swim motor program in the absence of electrical stimulation. Stimulation of serotonin-containing neurons also caused isolated nerve cords to produce the swim motor program but only if the volume of saline around the ganglia containing the stimulated neurons was small (less than $50 \mu \mathrm{l}$ ); under such conditions, serotonin was detected in the saline bathing the stimulated neurons. Serotonin also was found in blood from the sinus that contains the nerve cord of the leech. The concentrations of serotonin were correlated with the behavior of the animals whose blood was sampled; animals with the highest levels swam significantly more than did animals with low or intermediate levels; animals with the lowest levels of serotonin in their blood swam very little and were generally inactive. The concentrations of serotonin found in leech blood (10 to $100 \mathrm{nM}$ ) were similar to the lowest concentrations of serotonin that elicited swimming from isolated nerve cords. Experimentally elevating the concentration of serotonin in leech blood caused increased swimming activity. These observations suggest that serotonin is a modulator of neuronal control of swimming by the medicinal leech.
\end{abstract}

Biogenic amines influence the control of motor systems in many organisms. Motor areas of vertebrate brains, such as the basal ganglia, receive rich aminergic innervation, degeneration of which results in such motor abnormalities as parkinsonism (Hornykiewicz, 1966, 1973). In spinal cords, aminergic pathways may activate pattern generators for locomotion (Grillner, 1975). Invertebrate nervous systems, in which amines also activate motor programs (Granzow and Kater, 1977; Anderson and Barker, 1977; Livingstone et al., 1980), are useful for analyzing the cellular basis of aminergic actions. For example, studies of identified neural pathways in Aplysia have allowed detailed analyses of the mechanisms by which serotonergic neurons cause long term changes in synaptic

\footnotetext{
1 This work was supported by National Institutes of Health Grant NS14410 and National Science Foundation Grant BNS75-23567 to Dr. William B. Kristan, Jr. and by National Institutes of Health Postdoctoral Fellowship NS 06182-01 to A. L. W. I thank Dr. Kristan for his support, advice, and enthusiasm; Philip Lloyd for advice on the bioassay for serotonin; and Janis Weeks for her helpful criticism of this manuscript.

${ }^{2}$ Present address and that to which all reprint requests should be sent: Department of Neurobiology, Harvard Medical School, 25 Shattuck Street, Boston, MA 02115.
}

transmission (Klein and Kandel, 1978; Kupfermann, 1979).

This paper presents a study of the effects of serotonin on the neuronal generation of the motor program for swimming by the leech. ${ }^{3}$ The nervous system of the leech is useful for studying the effects of serotonin on a central pattern generator for several reasons: the motor program for swimming can be produced by isolated chains of ganglia (Kristan and Calabrese, 1976), a number of the motor and interneurons that participate in the control of swimming have been identified (Stent et al., 1978; Weeks, 1980), interneurons that elicit swimming in response to sensory stimuli have been identified (Weeks and Kristan, 1978; Weeks, 1980, 1981), and each segmental ganglion contains a small number (9 in ganglia 1 to 3,7 in ganglia 4 to 21) of identifiable serotonin-containing neurons (Lent et al., 1979; Marsden and Kerkut, 1969; Rude, 1969).

Although intact leeches often initiate swims in the apparent absence of external stimuli, isolated nerve cords

\footnotetext{
${ }^{3}$ Terms such as "swim" and "swimming" will be used as shorthand for longer phrases such as "motor program for swimming." SII will be used as an abbreviation for swim-initiating interneuron.
} 
rarely swim except in response to stimulation of whole nerves or of swim-initiating interneurons. The results presented in this paper demonstrate that: (1) isolated nerve cords do swim in the absence of external stimulation if serotonin is applied to them (first shown by Weeks, 1980) or if, under certain conditions, identified serotonergic neurons are stimulated; (2) stimulation of serotonergic neurons causes release of serotonin into the fluid surrounding the ganglia containing the stimulated neurons; (3) serotonin is found in the blood that bathes the nerve cord (the nerve cord of a leech lies inside a blood sinus); and (4) the levels of serotonin in the blood of leeches are related to the tendency of the leeches to swim in the absence of external stimuli. Some of these results have been published in an abstract (Willard, 1980).

\section{Materials and Methods}

Electrophysiology. The procedures of Kristan and Calabrese (1976) were used for the maintenance of the leeches (Hirudo medicinalis) and for the electrophysiological experiments on isolated nerve cords. Nerve cords were removed from animals and pinned in a dish of physiological saline (Nicholls and Baylor, 1968; as modified by Weeks, 1981) kept at $16^{\circ} \mathrm{C}$ by a cooling system. Individual neurons were viewed with dark-field illumination and were impaled with glass microelectrodes $(40$ to 60 megohms, filled with $4 \mathrm{~m}$ potassium acetate) for intracellular recording and stimulation. Glass-tipped suction electrodes were placed on segmental nerves for extracellular stimulation and recording. Semi-intact preparations were made as described by Kristan et al. (1974). The system of Ort et al. (1974) was used for numbering the ganglia and for the nomenclature of the nerves and neurons.

Serotonin was applied to whole nerve cords by replacing the physiological saline with saline to which serotonin had been added immediately before use. To apply serotonin to single ganglia or to pairs of ganglia within a nerve cord, small dams of Vaseline/mineral oil $(95 / 5 \%$, $\mathrm{w} / \mathrm{w}$ ) were constructed so that the saline bathing the desired ganglion or ganglia could be changed independently of the saline bathing the rest of the nerve cord (see the schematic drawing in Fig. 3). To determine the minimum number of connected ganglia that would swim in the absence of electrical stimuli, ganglia were cut away from whole cords until the remaining connected ganglia no longer swam.

Serotonin assays. Leeches were stretched rapidly, ventral side up, and pinned through their suckers. Their body walls were slit just anterior to the rear suckers to expose the ventral sinus in which the nerve cord lies. Samples of blood $(10$ to $50 \mu \mathrm{l})$ were collected with a Hamilton microsyringe and were diluted immediately with a 10-fold excess of $0.1 \mathrm{M} \mathrm{HCl}$ to stabilize the serotonin. To minimize the contribution of trauma-induced release to blood serotonin levels, no samples were collected later than $60 \mathrm{sec}$ after the first pin had been pushed through a sucker.

The procedure of Boireau et al. (1976), as modified by Goodrich et al. (1980), was used to isolate serotonin for subsequent bioassay. The samples were spun in an Eppendorf microfuge at $10,000 \mathrm{rpm}$ for $15 \mathrm{~min}$ and then the supernatants were brought to neutral $\mathrm{pH}$ with $\mathrm{KHCO}_{3}$ immediately before loading them on small $(0.4 \times 3 \mathrm{~cm})$ columns of Sephadex G-10 (Pharmacia) that had been activated by $0.5 \mathrm{M}$ formic acid for $30 \mathrm{~min}$. The columns had been washed with distilled water until the $\mathrm{pH}$ of the effluent was 7.0 before loading the samples. After sample application, the columns were washed with $6 \mathrm{ml}$ of distilled water to remove acetylcholine, catecholamines, indoleamines, and peptides that might interfere with the bioassay for serotonin. Serotonin then was eluted by a 3$\mathrm{ml}$ wash of $0.5 \mathrm{M}$ formic acid. The formic acid was evaporated in the dark over $\mathrm{NaOH}$ pellets and $\mathrm{CaSO}_{4}$ (Drierite) and the serotonin then was dissolved in $20 \mu \mathrm{l}$ of snail physiological saline (Kerkut and Meech, 1966). Recovery of known amounts of serotonin was routinely 90 to $95 \%$.

Serotonin was measured by a bioassay (Lloyd, 1978; P. E. Lloyd, personal communication) that is based on the positive inotropic effect of serotonin on snail hearts. Mature (3- to 8-gm) snails (Helix aspersa) were kept active for at least 6 days by feeding them lettuce and cucumber. Their hearts were removed and the ventricle was cannulated to allow constant perfusion with snail saline. A tension transducer monitored the strength of individual ventricular contractions. After 30 to $60 \mathrm{~min}$, the strength of individual contractions was constant but could be increased transiently by pulsed additions of serotonin to the perfusate. Calibration curves were obtained by injecting known amounts of serotonin into the perfusate before and after injecting aliquots $(10 \mu \mathrm{l})$ of test solutions containing serotonin that had been partially purified from leech blood. Two criteria were used to determine whether a particular heart would be used to measure the amounts of serotonin recovered from samples of leech blood: (1) only hearts whose contractile strength increased at least $5 \%$ to injections of $0.1 \mathrm{pmol}$ of serotonin were used; (2) only hearts producing linear increases in contractile strength to injections of saline containing between 0.1 and $0.8 \mathrm{pmol}$ of serotonin were used. Solutions of the serotonin from leech blood often needed to be diluted to lower the concentration to within the linear range of the hearts. At least three and usually five aliquots of each sample were tested; standard deviations for these replicate aliquots were less than $10 \%$ of the means. The concentration of serotonin in leech blood was calculated by dividing the total amount of serotonin recovered from the blood sample by the volume of the sample.

Experiments on intact animals. The behavioral preferences of individual leeches that had been kept in separate $500-\mathrm{ml}$ jars were observed for 10 to $60 \mathrm{~min}$ each day after placing them in a 5-gallon aquarium. In each aquarium, there were six test tubes and two jar lids on the bottom and one jar lid at the air-water interface; this arrangement allowed leeches to choose between exploring the aquarium by swimming or crawling and taking shelter beneath the covers or inside of the test tubes. Note was made of the amount of time each leech spent swimming, moving but not swimming, or not moving.

To study the effects of artificially elevated serotonin levels, leeches were anesthetized in $0.15 \%$ chlorobutanol for 6 to $8 \mathrm{~min}$ and then were injected with 50 to $100 \mu \mathrm{l}$ of 
$100 \mu \mathrm{M}$ serotonin; care was taken not to inject into the gut. Different control groups of leeches were injected with saline, were anesthetized but not injected, or were neither anesthetized nor injected. During recovery from anesthesia, leeches did not use their suckers for 30 to 60 min although they could swim. By 90 to 120 min after removal from the anesthetic, leeches did use their suckers and they appeared to have regained normal locomotor abilities. Subsequent observations of their behavior were made by a person who did not know which treatment any individual leech had received. The statistical significance of differences in the behavior of groups of animals was evaluated by a two-tailed Mann-Whitney $U$ test.

\section{Results}

Responses of isolated nerve cords to bath-applied serotonin. In normal saline, isolated, brainless nerve cords (ganglia 2 to 20 typically) rarely produced episodes of swimming in the absence of electrical stimulation of peripheral nerve roots (Kristan and Calabrese, 1976), of cut interganglionic connectives (data not shown), or of swim-initiating interneurons (Weeks and Kristan, 1978; Weeks, 1980, 1981). In saline containing serotonin, however, isolated nerve cords produced recurring swim episodes in the absence of any form of electrical stimulation. Such "spontaneous" episodes began 2 to 30 min after serotonin was added to the bath and continued for up to $3 \mathrm{hr}$ after the serotonin was washed out with normal saline. Figure 1 shows recordings of swim episodes that occurred before, during, and after a nerve cord was exposed to $5 \mu \mathrm{M}$ serotonin. Swims caused by serotonin were indistinguishable from electrically evoked swims as measured by the frequency and duration of bursts of motor neuron impulses or by motor neuron firing frequency within the bursts.
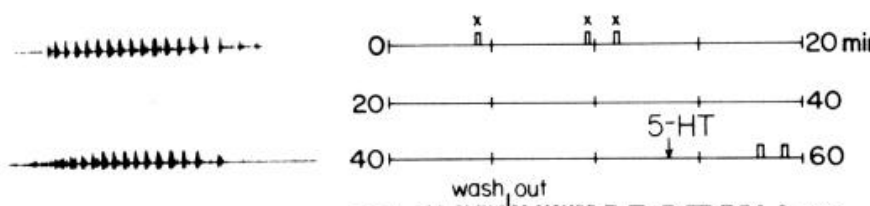

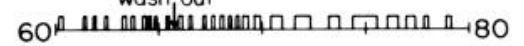

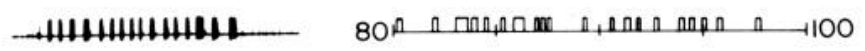

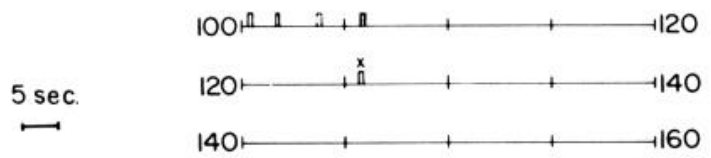

Figure 1. Episodes of swimming elicited from an isolated, brainless nerve cord by electrical stimuli and by serotonin. Left panel, The traces show extracellular recordings of bursts of motor neuron impulses in the dorsal branch of the posterior nerve during episodes elicited by an electrical stimulus to the nerve ( top trace), in the absence of electrical stimuli after $9 \mathrm{~min}$ in $5 \mu \mathrm{m}$ serotonin (middle trace), and in the absence of electrical stimuli $27 \mathrm{~min}$ after the serotonin had been washed out with normal saline (bottom trace). Right panel, The times of occurrence of swim episodes are indicated by boxes. Arrows indicate the times at which serotonin $(5-H T)$ was added to and washed out of the saline. $X$ 's above boxes indicate swim episodes that were evoked electrically; all others occurred in the absence of electrical stimulation.
The minimum concentration of serotonin necessary to cause swims in the absence of electrical stimuli ranged from 0.5 to $10 \mu \mathrm{M}$. More than $80 \%(19 / 23)$ of the nerve cords that would swim reliably in response to electrical stimuli in normal saline swam "spontaneously" in $5 \mu \mathrm{M}$ serotonin. Cords that did not swim in response to electrical stimuli almost never $(1 / 14)$ swam in serotonin even at the highest concentrations tested $(100 \mu \mathrm{M})$. Such nerve cords may have been damaged during dissection.

In concentrations of serotonin lower than $500 \mathrm{~nm}$, swims rarely occurred in the absence of electrical stimuli, but, after a single episode of swimming was evoked by an electrical stimulus, two or three additional episodes occurred without further stimulation (Fig. 2). This phenomenon was never observed in nerve cords that had not been exposed to serotonin. The minimum concentration of serotonin that caused this effect was $50 \mathrm{nM}$.

An index of how effectively a particular stimulus can elicit swimming is the minimum number of connected ganglia that can swim in response to that stimulus. The different types of electrical stimuli that cause isolated nerve cords to swim (stimulation of nerves; stimulation of swim-initiating interneurons (SIIs)) are not equally effective at causing short portions of nerve cords to swim. Stimulation of nerves does not cause chains of fewer than 6 ganglia to swim (Kristan and Calabrese, 1976); stimulation of SIIs causes as few as 2 ganglia to swim (Weeks, $1980,1981)$. In $10 \mu \mathrm{M}$ serotonin, chains of 6 or 7 ganglia usually swam $(8 / 11)$ and chains of $5(4 / 11), 4(3 / 11)$, or $3(3 / 11)$ ganglia occasionally swam. The swim episodes produced by chains of 3,4 , or 5 ganglia had fewer cycles and longer periods than did episodes produced by longer chains (data not shown). Single ganglia and pairs of ganglia did not swim in serotonin even at high concentrations (100 $\mu \mathrm{M})$. Thus, bath application of serotonin is more effective than stimulation of nerves but less effective than stimulation of SIIs at causing swimming by short chains of ganglia.

Effects of serotonin applied to portions of nerve cords. To test whether all of the neurons involved in generating swim episodes had to be exposed to serotonin in order to produce swim episodes in the absence of electrical stimuli, I applied serotonin to ganglia surrounded by dams. When serotonin was added to the saline surrounding 2 of

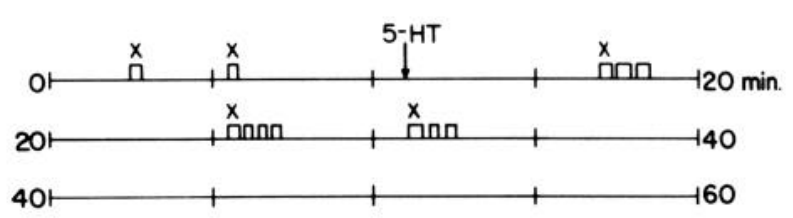

Figure 2. Serotonin-induced increases in the number of swim episodes following electrical stimuli. In normal saline, single episodes of swimming (indicated by boxes on the time line) occurred in response to electrical stimulation $(X)$ of a segmental nerve. After the saline was replaced by saline containing 100 nM serotonin $(5-H T)$, electrical stimulation of the same nerve elicited episodes of swimming that were followed by two or three additional episodes during the next 1 to $2 \mathrm{~min}$. Except for those episodes occurring within 2 min of a swim evoked by an electrical stimulus, no episodes occurred in the absence of electrical stimulation during the $48 \mathrm{~min}$ of exposure to serotonin. 

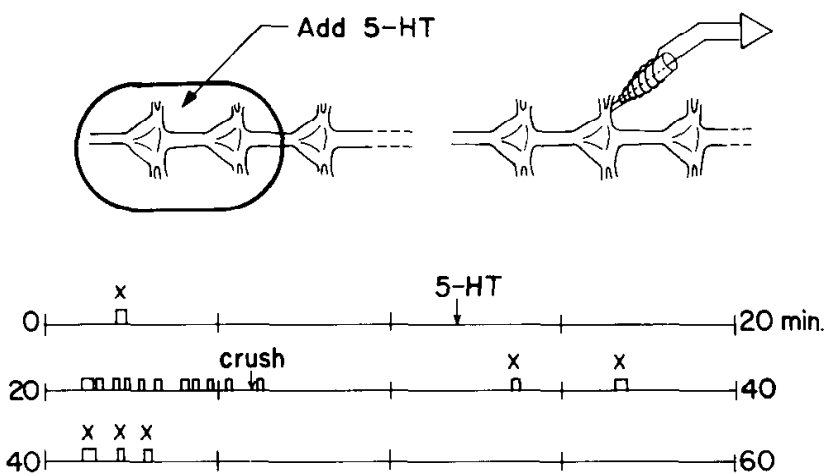

Figure 3. Swim episodes produced by a whole nerve cord after serotonin application to 2 of its ganglia. The 2 anteriormost ganglia of a nerve cord consisting of ganglia 2 to 20 were surrounded by a dam, as diagrammed in the upper part of the figure. Extracellular electrodes were used to monitor the segmental nerves of ganglia outside of the dam for swimming activity and also to stimulate those nerves. At the beginning of the experiment, when normal saline was bathing the entire nerve cord (including the 2 ganglia surrounded by the dam), stimulation of a segmental nerve caused an episode of swimming, but otherwise, no swimming occurred. About 9 min after the saline within the dam was replaced with serotonin-containing saline ( $5 \mu \mathrm{M} ; 5-H T)$, episodes of swimming occurred in the absence of any electrical stimuli. Crushing the connectives between the ganglia inside of the dam and the rest of the nerve cord (arrow) ended the occurrence of swims in the absence of electrical stimuli. The cord was, however, still able to swim in response to electrical stimuli, as indicated by the boxes (swims) beneath the $X$ 's that indicate the time at which electrical stimuli were delivered.

the 18 ganglia in an isolated nerve cord, swim episodes were produced subsequently by all of the ganglia, 16 of which were in normal saline (Fig. 3). These swim episodes were not caused by leakage of serotonin from the smaller chamber since they stopped when the connectives were crushed between the ganglia in serotonin and the rest of the nerve cord. The 16-ganglion cord was still capable of swimming in response to electrical stimuli (Fig. 3) as well as when serotonin was added to its own chamber (data not shown). Exposure of a single ganglion to serotonin also caused entire chains to swim but usually only immediately after episodes had been electrically evokedan effect also seen when entire cords were exposed to low concentrations of serotonin (Fig. 2).

Effects of stimulation of serotonin-containing neurons. Within each segmental ganglion of the leech, there are 7 (9 in ganglia 1 to 3 ) serotonin-containing neurons; these neurons are strongly electrically coupled (Lent and Fraser, 1977) and include the 2 Retzius cells, the largest neurons in leech ganglia. Intracellular stimulation of Retzius cells did not cause isolated nerve cords to swim when such experiments were performed in the standard 30-ml chamber (Weeks, 1980; A. L. Willard, unpublished observation). However, bath-applied serotonin requires minutes to cause swimming by isolated nerve cords; Nicholls and Kuffler (1964) showed that ions and small molecules can diffuse between intercellular and extraganglionic fluids in seconds. Thus, it was possible that released serotonin was being diluted by the large volume of saline around the isolated cord. To test this possibility,
I surrounded pairs of ganglia with dams, inserted a microelectrode into a Retzius cell in each ganglion and reduced the volume of saline around the ganglia to $50 \mu \mathrm{l}$ or less. The Retzius cells then were stimulated at 3 to 6 $\mathrm{Hz}$ for 5 to $10 \mathrm{~min}$. In the experiment shown in Figure 4, the nerve cord began to swim about $8 \mathrm{~min}$ after the stimulation of the Retzius cells was stopped. Comparable stimulation of mechanosensory neurons ( $T, P$, and N; Nicholls and Baylor, 1968), which do not contain serotonin (Sargent, 1977), did not cause swimming. The swims that followed Retzius cell stimulation were abolished by crushing the connective between the two parts of the nerve cord.

To test directly the hypothesis that released serotonin moves from intercellular to extraganglionic fluid, I did serotonin assays on aliquots of the saline surrounding ganglia in which neurons had been stimulated. Serotonin was detectable after stimulation of Retzius cells in normal saline but not after stimulation of Retzius cells in saline with low $\mathrm{Ca}^{2+}$ and high $\mathrm{Mg}^{2+}$, which blocks chemical synaptic transmission in the leech (Nicholls and Purves, 1970), nor after stimulation of $\mathrm{T}, \mathrm{P}$, or $\mathrm{N}$ cells (Table I).

Serotonin levels in leech blood. The leech nerve cord lies in the ventral blood sinus. Because released serotonin was found in extraganglionic fluid after stimulation of Retzius cells in vitro, it seemed likely that serotonin is in the blood bathing the nerve cords of intact leeches. To test this, I did serotonin assays on blood samples from the ventral sinuses of 5 leeches (see "Materials and Methods"). All of the samples contained detectable amounts of serotonin; concentrations ranged from 15 to $80 \mathrm{nM}$.

Correlation of behavior with serotonin levels in blood.
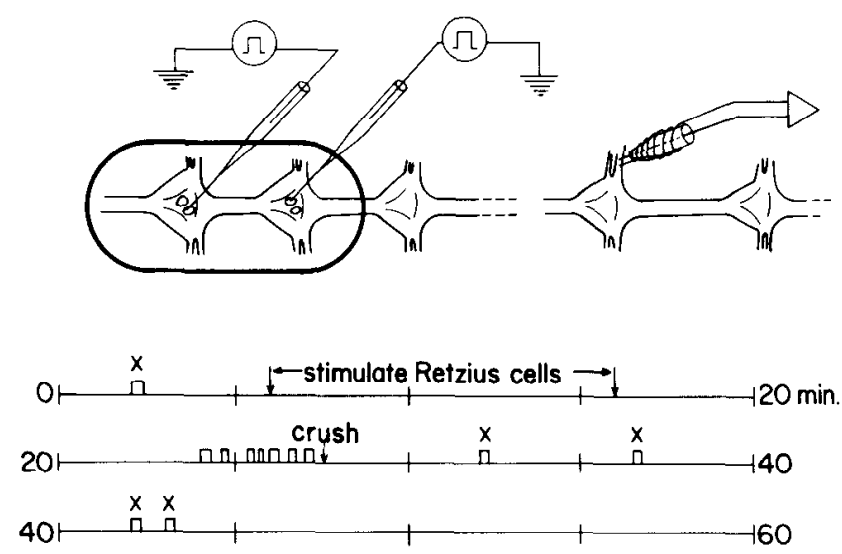

Figure 4. Swirnming produced by an isolated nerve cord after stimulation of Retzius cells. The 2 anteriormost ganglia of a chain of 18 (ganglia 3 to 20 ) were surrounded by a dam. One Retzius cell in each ganglion was impaled and stimulated to fire at 3 to $6 \mathrm{~Hz}$ for $10 \mathrm{~min}$ (see the diagram in the upper part of the figure). The volume of saline around the ganglia in the small chamber was less than $50 \mu \mathrm{l}$. About $8 \mathrm{~min}$ after cessation of stimulation of the Retzius cells, swim episodes (indicated by boxes on the time line) began to occur in the absence of electrical stimuli. Crushing the connectives between the ganglia in the smaller chamber and the rest of the nerve cord (arrow) ended the swim episodes, although the cord was still capable of swimming in response to electrical stimuli (marked by $X$ 's over the boxes). 
TABLE I

Effects of stimulating neurons on the concentration of serotonin in the saline around leech ganglia

Pairs of ganglia were surrounded with dams that allowed the volume of saline around the ganglia to be decreased to less than $50 \mu \mathrm{l}$. In each ganglion, single Retzius cells or pairs of sensory neurons (i.e., $2 \mathrm{~T}$ cells, $2 \mathrm{P}$ cells, or $2 \mathrm{~N}$ cells) were impaled with microelectrodes and stimulated to fire action potentials at 3 to $6 \mathrm{~Hz}$ for $10 \mathrm{~min}$. The amount of serotonin in the saline before and after stimulation of the neurons was assayed as described under "Materials and Methods." The assay could detect amounts of serotonin corresponding to concentrations greater than 8 nM.

\begin{tabular}{lccr}
\hline Cells Stimulated & Type of Saline & $\begin{array}{c}\text { Serotonin } \\
\text { Concentration } \\
\text { after } 10 \mathrm{~min} \\
\text { of Stimulation }\end{array}$ & $N$ \\
\hline Retzius & Normal & $n M$ & \\
Retzius & $0 \mathrm{Ca}^{2+}, \mathbf{4 0 ~} \mathrm{mM} \mathrm{Mg}^{2+}$ & $37 \pm 9$ & 5 \\
T, $\mathrm{P}$, or $\mathrm{N}$ & Normal & $<8$ & 5 \\
None & Normal & $<8$ & 6 \\
\hline
\end{tabular}

To determine whether different serotonin levels in leech blood were correlated with differences in the swimming behavior of intact leeches, I observed the behavior of individual animals before taking blood for serotonin assays. Within a laboratory population of several hundred animals, there were usually only a few that were swimming at any particular time. To ascertain whether particular individuals swam more than others, I kept the animals in separate containers and observed them for 10 to $60 \mathrm{~min}$ per day for 3 days (see "Materials and Methods"), measuring the time each animal spent swimming, moving but not swimming, or not moving. The behavior of most animals varied considerably from day to day. However, there were a few animals (designated "frequent swimmers") for which the average amount of time spent swimming was much greater than was the average for the entire population (Table II). There were also animals (designated "infrequent swimmers") which swam much less on the average than did the population. As shown in Table II, the frequent swimmers had significantly $(p<$ 0.008 ) higher serotonin concentrations in their blood than did the infrequent swimmers. The range of concentrations found in the blood of the animals with "unpredictable" behavior included concentrations found in frequent swimmers and in infrequent swimmers, but the mean for this group was significantly different from each of the other two groups $(p<0.02)$. Thus, levels of serotonin in the blood were correlated with the behavior of the animals, but they were not the absolute determinant of swimming behavior since some animals with high levels swam frequently or unpredictably and some animals with low levels swam infrequently or unpredictably.

Differences in serotonin levels also were correlated with differences in the amount of time that the animals spent moving by means other than swimming, such as crawling. Animals with the lowest levels of serotonin were not only infrequent swimmers but were also infrequent movers. Animals with unpredictable swimming behavior, which had higher serotonin levels than infrequent swimmers and lower levels than frequent swimmers, spent significantly more time moving $(p<0.002)$ than did infrequent swimmers and significantly less time

\section{TABLE II}

Behavioral preferences and serviunin levels in leeches

The animals were observed while they were in individual aquaria. Note was made of the amount of time spent swimming, moving but not swimming, and not moving. Animals that swam for at least $25 \%$ of each observation period were classified as "frequent swimmers." Those that swam less than $5 \%$ of every observation period were called "infrequent swimmers." Those that did not fall into one of these two categories for all 3 days of observation were called "unpredictable swimmers." When 60 animals were observed for $20 \mathrm{~min}$ on each of 3 days, 8 were classified as frequent swimmers, 19 were infrequent swimmers, and the other 33 were unpredictable swimmers. Of these animals, 5 frequent swimmers, 5 infrequent swimmers, and 10 unpredictable swimmers were observed for an additional 2 days and then blood samples were taken from them for serotonin analysis. This table shows the mean percentage of time $( \pm$ SD) each group spent swimming, moving but not swimming, or not moving. It also shows the mean concentration of serotonin found in the blood of the animals. The numbers in each column are significantly different $(p<0.02)$ except for the pair indicated by asterisks for which $p>0.1$. In some cases, as described in the text, the values of $p$ are less than 0.008 or 0.002 .

\begin{tabular}{|c|c|c|c|c|}
\hline Group & $\begin{array}{c}\text { Time } \\
\text { Swimming }\end{array}$ & $\begin{array}{c}\text { Time Moving } \\
\text { but Not } \\
\text { Swimming }\end{array}$ & $\begin{array}{l}\text { Time } \\
\text { Not Moving }\end{array}$ & $\begin{array}{c}\text { Concentration } \\
\text { of Serotonin } \\
\text { in Blood }\end{array}$ \\
\hline & $\%$ & $\%$ & $\%$ & $n M$ \\
\hline $\begin{array}{l}\text { Frequent } \\
\text { swimmers (5) }\end{array}$ & $42 \pm 14$ & $38 \pm 8^{*}$ & $19 \pm 9$ & $72 \pm 19$ \\
\hline $\begin{array}{l}\text { Unpredictable } \\
\text { swimmers } \\
\text { (10) }\end{array}$ & $11 \pm 4$ & $45 \pm 19^{*}$ & $44 \pm 20$ & $37 \pm 21$ \\
\hline $\begin{array}{l}\text { Infrequent } \\
\text { swimmers (5) }\end{array}$ & $1.5 \pm 0.5$ & $5 \pm 2$ & $92 \pm 2$ & $17 \pm 8$ \\
\hline
\end{tabular}

moving $(p<0.02)$ than did frequent swimmers (Table II). The difference in the amount of time spent moving by frequent and unpredictable swimmers was almost entirely attributable to the greater amount of time that frequent swimmers swam, since there was not a significant difference $(p>0.1)$ in the time these two groups spent in non-swimming locomotor behavior.

As described above (Fig. 2), isolated nerve cords that were bathed in physiological concentrations of serotonin (50 to $100 \mathrm{~nm}$ ) produced multiple episodes of swimming after a single electrical stimulus. This suggested that evoking a swim caused excitation that, when combined with the effects of the serotonin, caused additional swims. To look for comparable behavioral effects of evoking swims, I caused individual leeches to swim repeatedly. At the start of such experiments, leeches typically stopped swimming after contacting a surface, attached to it, and began to crawl. If they did not swim in the next $30 \mathrm{sec}$, they were prodded with a wire probe until they swam. After 25 or more proddings, leeches often started swimming again without prodding. To determine whether such multiple swim inductions caused elevation of serotonin in the blood, I assayed blood samples from previously infrequent swimmers that had been caused to swin repeatedly. The mean level for 4 such animals was $52 \pm$ $11 \mathrm{~nm}$ (range, 42 to $67 \mathrm{~nm}$ ). This was significantly different from the serotonin levels of infrequent swimmers $(p$ $<0.016$ ) but was not significantly different from the levels of either unpredictable or frequent swimmers ( $p$ $>0.1$.

To assess whether elevated serotonin levels caused or resulted from increased swimming, serotonin levels were 
increased experimentally and the behavioral consequences were determined. For at least $3 \mathrm{hr}$ after recovery from anesthesia, infrequent swimmers that had been injected with serotonin swam more frequently and for longer periods than did uninjected infrequent swimmers. The data shown in Table III are from two groups of animals, 5 injected with serotonin and 5 injected with saline. Both groups had significantly higher levels of blood serotonin $(p<0.004)$ than did the "infrequent swimmers" of Table II, and the serotonin-injected animals had significantly higher levels than did the salineinjected ones $(p<0.008)$. Serotonin-injected animals swam significantly more than did either uninjected $(p<$ $0.004)$ or saline-injected $(p<0.008)$ infrequent swimmers. Thus, trauma (anesthesia and injection) caused elevation of serotonin levels and increases in the amount of time spent swimming by animals, but injection of serotonin caused additional increases in both parameters.

Serotonergic neurons are excited during swimming and by stimuli that evoke swimming. The observation that an evoked swim was often followed by multiple swims in intact animals that had been prodded and in isolated nerve cords exposed to serotonin suggested that serotonin might be released during swimming. To monitor the activity of serotonergic neurons during swimming and in response to stimuli that evoked swims, I recorded from Retzius cells in isolated nerve cords and in semiintact preparations while stimulating nerves or pieces of attached skin. Retzius cells increased their firing rate during swims and were excited by both sub- and suprathreshold stimuli for swimming (Fig. 5).

Stimulation of single nerves excited not only the Retzius cells in the ganglion whose nerve was stimulated but also many and perhaps all of the other Retzius cells in the nerve cord (Fig. 5). This co-activation of Retzius cells in response to nerve stimulation was probably due to activation of interganglionic interneurons rather than to electrical coupling of Retzius cells in different ganglia. Intracellular stimulation of a single pair of Retzius cells did not cause excitation of Retzius cells in other ganglia (data not shown). The $S$ interneuron (Frank et al., 1975) is an identified interganglionic interneuron that is excited by nerve shocks similar to those that cause activation of

\section{TABLE III}

Effects of serolonin or saline injections on behavior and serotonin levels of infrequently swimming leeches

Ten infrequently swimming leeches were injected with $100 \mu \mathrm{l}$ of either $10^{4} \mathrm{M}$ serotonin or saline. Between 2 and $3 \mathrm{hr}$ after the injections, they were observed for $10 \mathrm{~min}$ (see "Materials and Methods") to see how often and how long they swam. At $3 \mathrm{hr}$, blood samples were taken for serotonin assays. The data for uninjected infrequent swimmers are from Table II. The results are means $\pm \mathrm{SD}$. The numbers in each column are significantly different from each other $(p<0.008$ and, in some cases, $p<0.004$; see text).

\begin{tabular}{lccc}
\hline Group & $\begin{array}{c}\text { Time } \\
\text { Swimming }\end{array}$ & $\begin{array}{c}\text { Number } \\
\text { of Swims } \\
\text { per 10 min }\end{array}$ & $\begin{array}{c}\text { Concentration } \\
\text { of Serotonin } \\
\text { in Blood }\end{array}$ \\
\hline Serotonin injected (5) & $19 \pm 8$ & $7 \pm 2$ & $69 \pm 11$ \\
Saline injected (5) & $4 \pm 3$ & $1 \pm 1$ & $49 \pm 7$ \\
Uninjected infrequent & $1.5 \pm 0.5$ & $-^{a}$ & $17 \pm 8$ \\
swimmers (5) & & & \\
\hline$"$ ", not noted. & & & \\
\end{tabular}

Retzius cells and by stimulation of skin (Laverack, 1969; Bagnoli et al., 1972). Thus, the $\mathrm{S}$ cell was a candidate for the interneuron(s) that mediated activation of Retzius cells in response to nerve shock or skin stimulation. Intracellular stimulation of the $S$ cell caused excitatory synaptic potentials in all Retrius cells tested. $S$ was not the only interganglionic interneuron that excited Retzius cells; at least two other classes of synaptic potentials, which did not match action potentials in $\mathrm{S}$, were evoked in all Retzius cells by nerve shock. $S$ is unlikely to excite Retzius cells during swimming since it does not fire during swimming (J. C. Weeks, personal communication).

Regardless of the pathways by which the Retzius cells are activated during swimming, the fact that they are active during swimming and are excited by stimuli that cause swimming makes them (and the other serotonincontaining neurons to which they are strongly electrically coupled) likely candidates for the neurons that cause elevated blood levels of serotonin following multiple swim episodes.

Comparison of activity of SIIs during swims in normal saline and during swims caused by serotonin. Two identified interneurons, cells 204 and 205, participate in the initiation and maintenance of swim episodes in normal saline (Weeks and Kristan, 1978; Weeks, 1980, 1981; J. C. Weeks, manuscript in preparation). All known means of evoking episodes of swimming - tactile stimulation of skin, electrical stimulation of segmental nerves or of intersegmental connectives, or intracellular stimulation of an individual SII-cause excitation and increased impulse frequency of cells 204 and 205 (Weeks and Kristan, 1978; Weeks, 1980, 1981; J. C. Weeks, manuscript in preparation). Stimulation of any one of the SIIs to fire at 10 to $30 \mathrm{~Hz}$ causes isolated nerve cords or semi-intact preparations to begin swimming; during swims, all SIIs become active (Weeks and Kristan, 1978; Weeks, 1980, 1981; J. C. Weeks, manuscript in preparation). In addition to initiating swimming, the SIIs also influence the period of swimming cycles: for example, when a 204 cell is caused to increase its firing rate during an ongoing episode of swimming, cycle periods decrease (Weeks and Kristan, 1978).

Thus, one hypothesis to explain how serotonin causes swimming is that serotonin increases the excitability of SIIs; such an increase could result from changes in membrane properties of SIIs, from altered synaptic inputs to SIIs, or from both. Two types of observation demonstrated that SIIs participate in the initiation and maintenance of swims caused by serotonin. First, intracellular recordings from SIIs during swims caused by serotonin showed that SIIs received excitation and increased their firing rate (Fig. 6) as they do during swims evoked by electrical or mechanical stimuli in normal saline. Serotonin and mechanical or electrical stimuli thus activate very similar, and perhaps identical, excitatory inputs to SIIs. Second, depolarization of individual 204 cells during ongoing episodes of serotonin-induced swimming caused shortening of the swim cycle period (data not shown).

On the other hand, serotonin did not cause detectable changes in the membrane properties (input resistance, current-voltage relation, and the ability to generate bursts of action potentials) of SIIs nor did it change the 

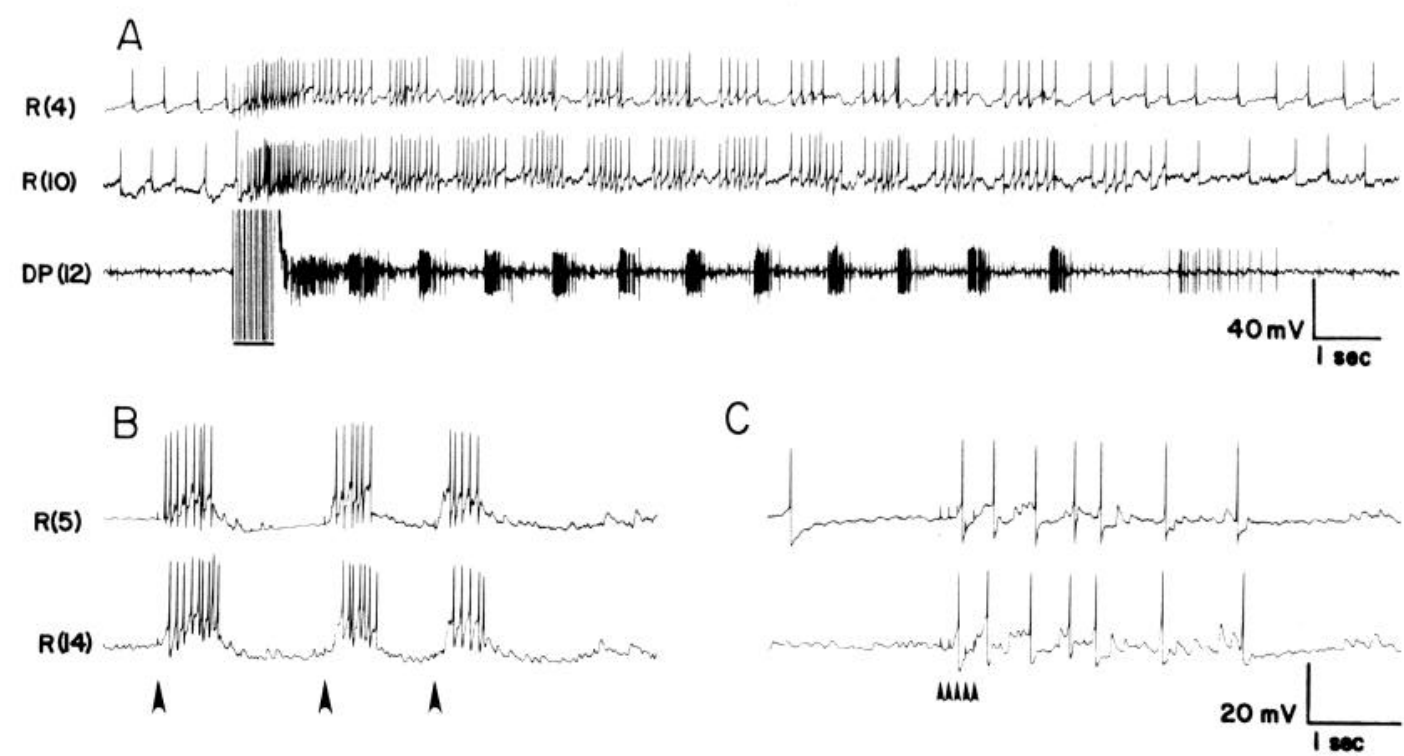

Figure 5. Excitation of Retzius cells during swimming and by electrical stimuli. $A$, A train of shocks (underlined) was delivered to a segmental nerve of ganglion 12 while recordings were being made intracellularly from Retzius cells in ganglia 4 and $10(R(4)$ and $R(10))$ of an isolated, brainless nerve cord (ganglia 2 to 20 ). The shocks caused the Retzius cells to depolarize and to increase their firing rates. The shocks also elicited an episode of swimming (as shown by the bursts of impulses in the extracellular record from the dorsal branch of the posterior nerve $(D P(12))$ during which the Retzius cells fired phasically and at higher frequency than before the shocks or after the swim ended. Note that the 2 Retzius cells received similar excitation. $B$ and $C$, In a different preparation, intracellular records were made from Retzius cells in ganglia 5 and $14(R(5)$ and $R(14))$ of a nerve cord (ganglia 3 to 20 ) while the cut anterior end of the nerve cord $(B)$ or the cut end of a peripheral nerve $(D P)$ of ganglion 17 was being stimulated extracellularly. In $B$, three single shocks (indicated by arrows) each evoked strong excitation of both Retzius cells. In $C$, a train of five shocks caused a weaker, but longer lasting excitation of the 2 neurons. The time and voltage scales in $C$ also apply to $B$.
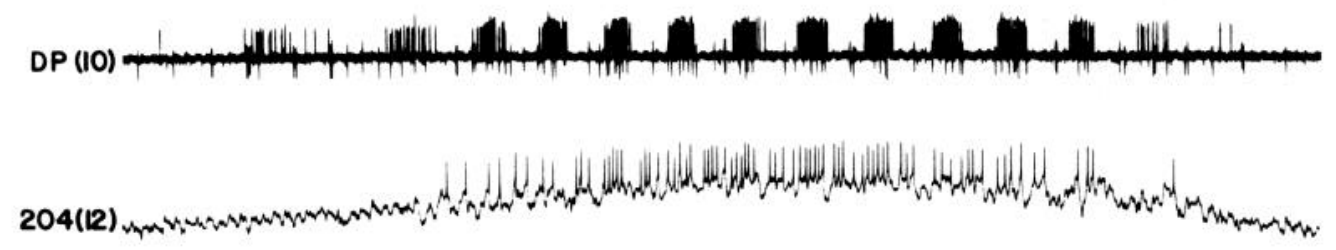

$$
20 \mathrm{mv} \frac{L}{1800}
$$

Figure 6. Activity in a swim-initiating interneuron during a serotonin-evoked episode of swimming. The upper trace is an extracellular recording of motor neuron impulses during swimming that occurred in a nerve cord that had been exposed to $1 \mu \mathrm{m}$ serotonin for $23 \mathrm{~min}$. The lower trace, an intracellular record of cell 204 activity during this swim, shows that cell 204 receives excitation before and during the swim episode but that swimming begins before firing in cell 204. $D P(10)$, dorsal branch of the posterior nerve, ganglion 10; 204(12), cell 204, ganglion 12.

ability of the SIIs to activate the swim pattern generator. The swim-inducing capability of such sensory stimuli as stroking of the skin in semi-intact preparations or electrical stimulation of segmental nerves of isolated cords were unchanged also. Intracellular stimulation of individual mechanosensory neurons, which does not cause swimming in normal saline (Kristan, 1979), also did not cause swimming in serotonin.

Another test for the effects of serotonin on SIIs was to record from SIIs while intracellularly stimulating Retzius cells. No synaptic connections between Retzius cells and the SIIs were seen. In addition, in recordings made from many other identified and unidentified neurons while stimulating Retzius cells, the only cells that were observed to receive synaptic input from the Retzius cells were the other serotonin-containing neurons to which the Retzius cells are coupled electrically (Lent and Fraser, 1977).

Thus, although the SIIs participate in the initiation and maintenance of swims caused by serotonin, these neurons do not appear to be the primary target of serotonin. 


\section{Discussion}

Serotonin as a circulating modulator. Four lines of evidence suggest that serotonin is a circulating modulator in the leech. (1) Serotonin is present in the blood that bathes the nerve cord. This is also the case in other animals in which serotonin has been proposed as a neurohormone (Livingstone et al., 1980). (2) The levels of serotonin in leech blood are related to the tendency of the animals to swim. Leeches which normally swam frequently were among those with the highest levels of serotonin, while leeches which swam rarely had the lowest levels of serotonin. When the levels of serotonin were elevated artificially by injections, animals which previously had swum infrequently swam significantly more frequently. (3) Addition of serotonin to the saline bathing an isolated nerve cord, or even a small part of an isolated nerve cord, has a very specific effect: it causes production of episodes of the motor program for swimming. The minimum effective concentration, $50 \mathrm{nM}$, is similar to the concentrations of serotonin in the blood of active leeches. (4) Stimulation of identified serotonin-containing neurons causes release of serotonin into the saline around the ganglia containing the stimulated neurons. When the volume of saline is similar to the volume of blood that normally bathes the nerve cord, such stimulation elevates serotonin levels sufficiently to cause the nerve cord to swim in the absence of electrical stimuli. In contrast, SIIs, which presumably communicate with the central pattern generator for swimming via "conventional" synapses, cause swimming no matter how much saline bathes the nerve cord.

Physiological role of circulating serotonin. Serotonin appears to change the probability of swimming without affecting the actual performance of this motor program. In other systems, amines have been shown to affect both the "vigor" of a rhythmic motor pattern and the likelihood of its occurrence (Granzow and Kater, 1977; Anderson and Barker, 1977) or to affect the kinetics of a rhythmic motor pattern without affecting the probability of its occurrence (Cooke and Hartline, 1975). What then is the normal physiological role of serotonin in the control of behavior by the leech?

There are two reasons why elevation of extracellular levels of serotonin is not the mechanism by which individual episodes of swimming are initiated normally. First, the lag between time of serotonin elevation and time of occurrence of swimming is too long-minutes rather than the usual seconds or fractions of a second that it takes to produce swimming in response to tactile stimulation of skin or depolarization of an SII. Second, the correlation between serotonin levels and swimming is not absolute. For instance, the animal with the lowest levels of serotonin can swim, and even the most active animals do not swim as frequently or as regularly as does the isolated nerve cord that has been exposed to high levels of serotonin.

At physiological concentrations of serotonin (less than $100 \mathrm{~nm}$ ), isolated nerve cords do not swim continuously (Fig. 2); thus, the response of isolated nerve cords to higher concentrations of serotonin may result from exaggerations of normally rather subtle effects. In other animals, such as Aplysia, serotonin modulates sensory inputs (Klein and Kandel, 1978; Kupfermann, 1979). I saw no evidence for such an effect of serotonin in leeches; thresholds for sensory effects on swimming were unchanged by serotonin.

The normal physiological role of serotonin may not be to cause increased swimming behavior specifically but rather to regulate a behavioral "state," such as arousal; i.e., swimming might be only one of several behaviors influenced by serotonin. This idea is supported by the observation that leeches with different levels of serotonin in their blood sometimes differed from each other in several behaviors (Table II). In particular, unpredictable swimmers, which had intermediate levels of serotonin in their blood, were significantly more active than infrequent swimmers, both with respect to swimming and to non-swimming locomotion. Frequent swimmers, which had the highest levels of serotonin, swam significantly more than unpredictable swimmers but did not differ significantly from them in the fraction of time spent in non-swimming locomotion (Table II). The following is a hypothetical sequence of events in which changes in serotonin levels could be behaviorally significant: (1) external stimuli, such as those caused by prey or predators, cause increased activity in the serotonin-containing neurons; (2) the increased activity causes an increase in the levels of circulating serotonin; (3) the increased serotonin levels cause increases in such behaviors as nonsensory triggered episodes of swimming; (4) the increased locomotor activity leads the leech to its prey or away from its predator. Besides being speculative, this scheme is likely not to be the only way in which locomotive activity is modulated, since hungry leeches are known to be much more active and responsive to tactile stimuli than are sated leeches (Mann, 1962). This behavioral difference also could be due to variations in blood levels of serotonin.

In addition to its central actions, serotonin has peripheral effects. Stimulation of Retzius cells, the only serotonergic neurons with peripherally directed axons, influences mucus release (Lent, 1973) and can accelerate muscle relaxation (Mason et al., 1979). Inhibitory synaptic potentials in body wall muscles and the responses of body wall muscles to iontophoretically applied serotonin are similar in their ionic dependence and pharmacologic sensitivity (Sawada and Coggeshall, 1976; Sawada et al., 1976). The effects of circulating serotonin on peripheral tissues that respond to serotonin have not been examined yet.

Cellular and molecular mechanisms of action. Although cells which release serotonin have been identified, the target neurons are not known yet. In theory, serotonin could increase the probability of swimming by lowering thresholds to sensory stimuli, by activating swim-initiating interneurons, or by directly activating the cells in the central pattern generator. Serotonin-induced changes in responses to sensory stimuli or to stimulation of individual mechanosensory neurons were not detected. Consistent changes were not detected in the activity of swim-initiating interneurons or in their effectiveness as swim initiators. However, the fact that the identified swim-initiating interneurons are active during serotonininduced swimming suggests that serotonin activates pathways similar to those activated by sensory stimuli. 
The ability of serotonin to induce swimming in the absence of overt sensory stimuli may aid in identifying nonsensory pathways by which leeches initiate swimming.

Until the cells that are affected by serotonin are known, it will be difficult to deduce its molecular mechanism of action. The fact that its effects take minutes to be seen and then last for minutes to hours suggests that it may be a modulator that acts slowly. In other systems, modulators with such slow time courses of action often act via second messengers such as cyclic nucleotides (Daly et al., 1980).

\section{References}

Anderson, W. W., and D. L. Barker (1977) Activation of a stomatogastric motor pattern generator by dopamine and $\mathrm{L}$ DOPA. Soc. Neurosci. Abstr. 3: 171.

Bagnoli, P., M. Bonnelli, and F. Magni (1972) A fast conducting system in the central nervous system of the leech IIirudo medicinalis. Arch. Ital. Biol. 110: 35-51.

Boireau, A., J. P. Ternaux, S. Bourgoin, F. Hery, J. Glowinski, and M. Hamon (1976) The determination of picogram levels of 5-HT in biological fluids. J. Neurochem. 26: 201-204.

Cooke, I. M., and D. K. I Iartline (1975) Neurohormonal alteration of integrative properties of the cardiac ganglion of the lobster Homarus americanus. J. Exp. Biol. 63: 33-52.

Daly, J. W., B. J. Hoffer, and R. K. Dismukes (1980) Mechanisms of regulation of neuronal sensitivity. Neurosci. Res. Program Bull. 18: 325-456.

Frank, E., J. K. S. Jansen, and E. Rinvik (1975) A multisomatic axon in the central nervous system of the leech. J. Comp. Neurol. 159: 1-13.

Goodrich, J. T., P. Bernd, D. Sherman, and M. D. Gershon (1980) Phylogeny of enteric serotonergic neurons. J. Comp. Neurol. 190: 15-28.

Granzow, B., and S. Kater (1977) Identified higher-order neurons controlling the feeding motor program of Helisoma. Neuroscience 2: 1049-1063.

Grillner, S. (1975) Locomotion in vertebrates-central mechanisms and reflex interaction. Physiol. Rev. 55: 247-304.

Hornykiewicz, O. (1966) Dopamine and brain function. Pharmacol. Rev. 18: 925-964.

Hornykiewicz, O. (1973) Dopamine in the basal ganglia. Br. Med. Bull. 29: 172-178.

Kerkut, G. A., and R. W. Meech (1966) The internal chloride concentration of the $\mathrm{H}$ and $\mathrm{D}$ cells in the snail brain. Comp. Biochem. Physiol. 19: 819-832.

Klein, M., and E. R. Kandel (1978) Presynaptic modulation of voltage-dependent $\mathrm{Ca}^{2+}$ current: Mechanism for behavioral sensitization in Aplysia californica. Proc. Natl. Acad. Sci. U. S. A. 75: 3512-3516.

Kristan, W. B., Jr. (1979) Neuronal changes related to behavioral changes in chronically isolated segments of the medicinal leech. Brain Res. 167: 215-220.

Kristan, W. B., Jr., and R. L. Calabrese (1976) Rhythmic swimming activity in neurons of the isolated nerve cord of the leech. J. Exp. Biol. 65: 643-668.

Kristan, W. B., Jr., G. S. Stent, and C. A. Ort (1974) Neuronal control of swimming in the medicinal leech. I. Dynamics of the swimming rhythm. J. Comp. Physiol. 94: 97-119.

Kupfermann, I. (1979) Modulatory actions of neurotransmitters. Annu. Rev. Neurosci. 2: 447-465.

Laverack, M. S. (1969) Mechanoreceptors, photoreceptors and rapid conduction pathways in the leech, Hirudo medicinalis. J. Exp. Biol. 50: 129-140.

Lent, C. M. (1973) Retzius cells: Neuronal effectors controlling mucus release by the leech. Science 179: 693-696.

Lent, C. M., and B. M. Frazer (1977) Connectivity of the monoamine-containing neurons in central nervous system of leech. Nature 26: 844-847.

Lent, C. M., J. Ono, K. T. Keyser, and H. J. Karten (1979) Identification of serotonin within vital stained neurons from leech ganglia. J. Neurochem 32: 1559-1563.

Livingstone, M. S., R. M. Harris-Warrick, and E. A. Kravitz (1980) Serotonin and octopamine produce opposite postures in lobsters. Science 208: 76-79.

Lloyd, P. E. (1978) Distribution and molecular characteristics of cardioactive peptides in the snail, Helix aspersa. J. Comp. Physiol. 128: 269-276.

Mann, K. H. (1962) Leeches (Hirudinea). Their Structure, Physiology, Ecology and Embryology, Pergamon Press, Elmsford, NY.

Marsden, C. A., and G. A. Kerkut (1969) Fluorescent microscopy of the 5HT- and catecholamine-containing cells in the central nervous system of the leech Hirudo medicinalis. Comp. Biochem. Physiol. 31: 851-862.

Mason, A., A. J. Sunderland, and L. D. Leake (1979) Effects of leech Retzius cells on body wall muscles. Comp. Biochem. Physiol. (C) 63: 359-361.

Nicholls, J. G., and D. A. Baylor (1968) Specific modalities and receptive fields of sensory neurons in the CNS of the leech. J. Neurophysiol. 31: 740-756.

Nicholls, J. G., and S. W. Kuffler (1964) Extracellular space as a pathway for exchange between blood and neurons in the central nervous system of the leech: Ionic composition of glial cells and neurons. J. Neurophysiol. 27: 645-671.

Nicholls, J. G., and D. Purves (1970) Monosynaptic chemical and electrical connexions between sensory and motor cells in the central nervous system of the leech. J. Physiol. (Lond.) 209: 647-667.

Ort, C. A., W. B. Kristan, Jr., and G. S. Stent (1974) Neuronal control of swimming in the medicinal leech. II. Identification and connections of motor neurons. J. Comp. Physiol. 94: 121154.

Rude, S. (1969) Monoamine-containing neurons in the central nervous system and peripheral nerves of the leech Hirudo medicinalis. J. Comp. Neurol. 136: 349-372.

Sargent, P. B. (1977) Synthesis of acetylcholine by excitatory motoneurons in central nervous system of the leech. J. Neurophysiol. 40: 453-460.

Sawada, M., and R. E. Coggeshall (1976) Ionic mechanism of 5hydroxytryptamine induced hyperpolarization and inhibitory junctional potential in body wall muscle cells of Hirudo medicinalis. J. Neurobiol. 7: 63-73.

Sawada, M., J. M. Wilkinson, D. J. McAdoo, and R. E. Coggeshall (1976). The identification of two inhibitory cells in each segmental ganglion of the leech and studies on the ionic mechanism of the inhibitory junctional potentials produced by these cells. J. Neurobiol. 7: 435-445.

Stent, G. S., W. B. Kristan, Jr., W. O. Friesen, C. A. Ort, M. Poon, and R. L. Calabrese (1978) Neuronal generation of the leech swimming movement. Science 200: 1348-1356.

Weeks, J. C. (1980) The roles of identified interneurons in initiating and generating the swimming motor pattern of leeches. Doctoral dissertation, University of California, San Diego.

Weeks, J. C. (1981) The neuronal basis of leech swimming: Separation of swim initiation, pattern generation, and intersegmental coordination by selective lesions. J. Neurophysiol. 45: 698-723.

Weeks, J. C., and W. B. Kristan, Jr. (1978) Initiation, maintenance and modulation of swimming in the medicinal leech by the activity of a single neuron. J. Exp. Biol. 77: 71-88.

Willard, A. L. (1980) Serotonin increases the probability that the leech nervous system will produce the motor program for swimming. Soc. Neurosci. Abstr. 6: 27. 